\title{
Minimizing Nordmøre Grid Bar Spaces in an Australian Penaeid Fishery
}

\author{
MATT K. BROADHURST, RUSSELL B. MILLAR, and ANDREW DINGLE
}

\section{Introduction}

Concerns about penaeid-trawl discard mortality, and especially juveniles of important fish stocks, have led to various resolution strategies (Hall and Mainprize, 2005). Excluding closures, the most common approach has been to locate bycatch reduction devices (BRD) anterior to the trawl codend (Broadhurst, 2000).

One of the most effective BRD is the Nordmøre grid, which comprises separated bars (e.g., 20-100 mm) and is installed at angles of approximately $30^{\circ}-48^{\circ}$ in the extension section

Matt K. Broadhurst (matt.broadhurst@dpi.nsw. gov.au) is with the NSW Department of Primary Industries, Fisheries Conservation Technology Unit, National Marine Science Centre, P.O. Box 4321, Coffs Harbour, NSW 2450, Australia, and Marine and Estuarine Ecology Unit, School of Biological Sciences, University of Queensland, Brisbane, QLD 4072, Australia. Russell B. Millar is with the Department of Statistics, The University of Auckland, Private Bag 92019, Auckland, New Zealand. Andrew Dingle is with Andrew Dingle Electrical, 34 Taylor St., Narrabri, NSW 2390, Australia.

doi: https://doi.org/10.7755/MFR.80.1.2

ABSTRACT-The effects of reducing bar spaces in a generic Nordmøre grid used in an Australian penaeid-trawl fishery were investigated within an objective of maximising bycatch reduction while maintaining target catches. Compared to a conventional Nordmøre grid with $20 \mathrm{~mm}$ bar spaces, those with 16 and $18 \mathrm{~mm}$ bar spaces maintained the retained weights of school prawns, Metapenaeus macleayi, and with no effects on size selectivity, but caught incrementally lower weights of total fish, which for the 16 mm grid was significant (mean reduced by $\sim 26 \%$ ). The results imply that Nordmøre grid bar spaces can be reduced to a size approaching the width of the largest penaeids with no commercial impacts. of trawls, with or without an anterior guiding panel and either a horizontal or triangular escape exit at the top (Isaksen et al., 1992; Broadhurst et al., 1996; Brewer et al., 1998; Silva et al., 2012). Intuitively, the performance of the Nordmøre grid should be strongly affected by the bar spaces relative to the sizes of the penaeids and unwanted bycatch. However, few studies have been published in the primary literature that test for any association between bar spacing and catches in penaeid trawls (but see Silva et al., 2012).

One penaeid-trawl fishery in which the Nordmøre grid has been successfully implemented, but for which there are no formal data assessing variations among bar spaces, occurs in estuaries in New South Wales (NSW), Australia. This fishery involves 115 small trawlers (mostly $<10 \mathrm{~m}$ and $110 \mathrm{~kW}$ ) diurnally targeting school prawns, Metapenaeus macleayi (all $<25 \mathrm{~mm}$ carapace length; CL) mostly during the Austral summer for annual catches of $400 \mathrm{t}$ per annum valued at almost AUD \$3 million. A Nordmøre grid with $20 \mathrm{~mm}$ bar spaces was adopted by many fishermen 25 years ago and was shown to reduce total bycatch by $>70 \%$ while maintaining catches of school prawns (Broadhurst et al., 1996). The $20 \mathrm{~mm}$ bar spacing was chosen based on school prawns being similar in size to those in European fisheries (Pandalus borealis) (Isaksen et al., 1992). However, the appropriateness of this spacing has never been tested. Our aim here was to assess the effects on target and bycatch species when bar spaces are reduced to a size approaching the maximum carapace thickness of the largest school prawns.

\section{Methods}

The work was done in the Clarence River (lat. 29 $27 \mathrm{~S}$, long. $153^{\circ} 12^{\prime} \mathrm{E}$ ), NSW, Australia using one commercial double-rigged otter trawler (10 m) fishing across sand (2-20 m depth) over six days. The trawls used were identical four-seam Florida Flyers ${ }^{1}$ (7.35 m headlines) made from $42 \mathrm{~mm}$ stretched mesh opening (SMO) polyethylene (PE) netting $(1.2 \mathrm{~mm}$ diameter- $\varnothing$ twisted twine) (Fig. 1a). The trawls were attached to $2.89 \mathrm{~m}$ sweeps and cambered otter boards $(1.07 \times$ $0.76 \mathrm{~m} ; 54 \mathrm{~kg}$ ) and had extension sections made from $41 \mathrm{~mm}$ SMO PE netting ( $1.3 \mathrm{~mm} \varnothing$ twisted twine) measuring $75 \mathrm{~N} \times 100 \mathrm{~T}$ (Fig. 1b). Each extension section had a guiding panel $\left(28^{\circ}\right)$ terminating at the base of an inverted tombstone-shaped aluminium frame $(402 \times 602 \mathrm{~mm}$ and $10 \mathrm{~mm}$ square bar) secured at an angle of $45^{\circ}$ and with an opening in the top of the codend (Fig. 1b). Conventional codends $(120 \times 75 \mathrm{~B})$ made from squareshaped mesh $(27 \mathrm{~mm}$ SMO and 1.3 $\mathrm{mm} \varnothing$ braided polyamide twine hung on the bar) were attached to the extension sections behind the aluminium frame (Fig. 1b).

Three grids were constructed so that they could be easily inserted into, and removed from, the two aluminum frames (Fig. 1b). All grids were made from identical materials (10 and 12 $\mathrm{mm} \varnothing$ aluminium rod bars and frames) and had the same external dimensions $(400 \times 600 \mathrm{~mm})$ but different numbers of bars (and therefore spaces): 12 (19.69 mm; conventional grid); 13

${ }^{1}$ Mention of trade names or commercial firms does not imply endorsement by the National Marine Fisheries Service, NOAA. 


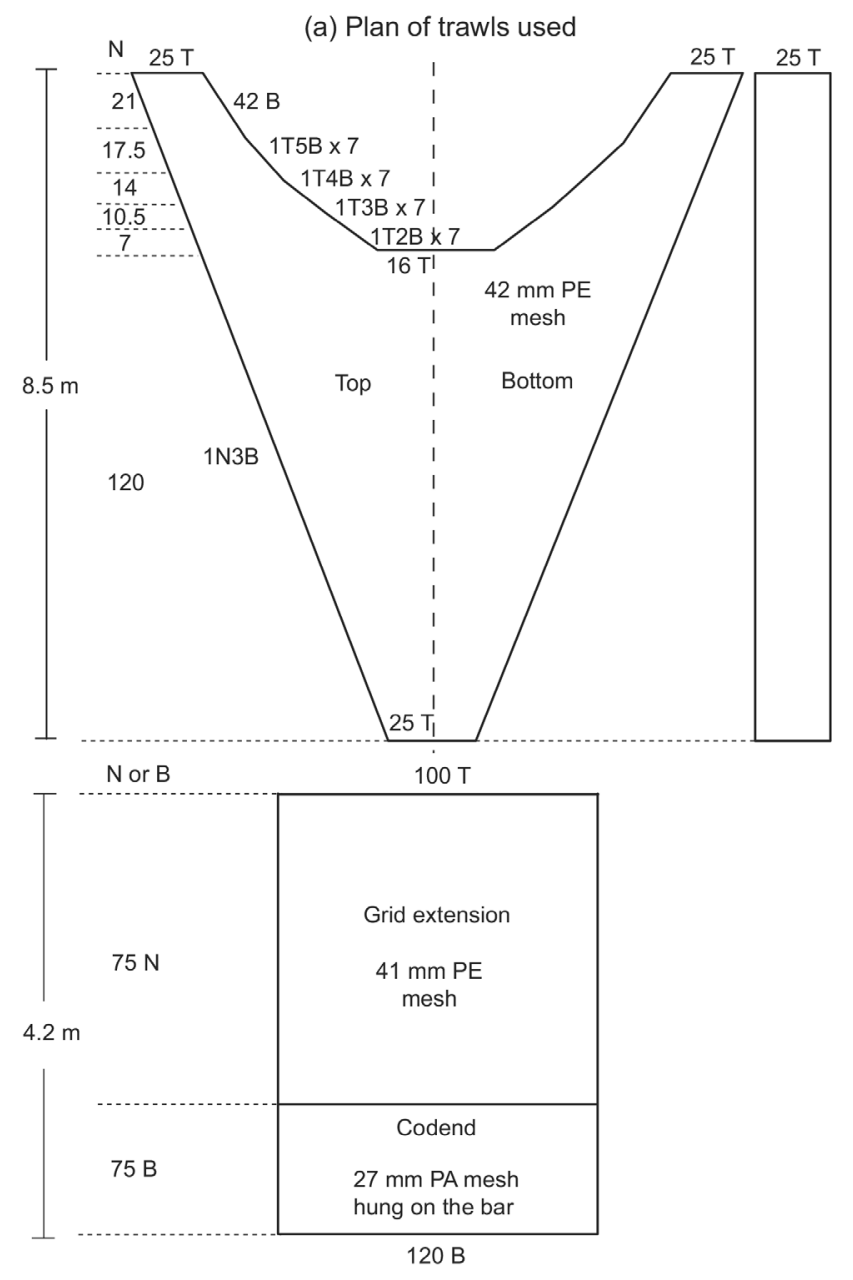

(b) Extension section with grid frame and codend
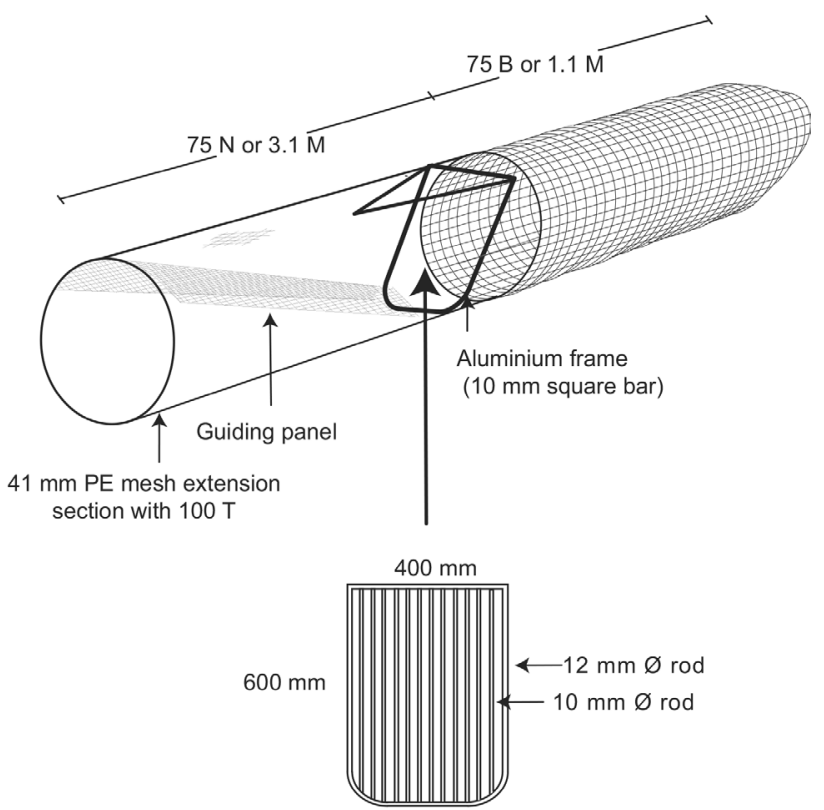

$20 \mathrm{~mm}$ grid

Figure 1.- The (a) trawls used and (b) extension section with grid frame (and $20 \mathrm{~mm}$ grid) and square-mesh codend (PE: polyethylene; PA: polyamide; Ø: diameter).

$(17.57 \mathrm{~mm})$; and $14(15.73 \mathrm{~mm})$ bars. These treatments were termed the 20 , 18 , and $16 \mathrm{~mm}$ grids, respectively.

The narrowest bar space $(16 \mathrm{~mm})$ was chosen to be slightly wider than the maximum carapace thickness of the largest school prawns, and based on established morphological relationships between CL and maximum carapace width $(\mathrm{CW})$ and height $(\mathrm{CH})$ derived for individuals (5-25 mm CL) in the Clarence River by Broadhurst et al. (2004). Both CW and $\mathrm{CH}$ were deemed important because the orientation of school prawns during passage through the grid remains unknown. Following an absence of sexual dimorphism, common regressions were cal- culated as $\mathrm{CH}=0.638 \mathrm{CL}-0.766$ and $\mathrm{CW}=0.511 \mathrm{CL}-0.496$; which for a $25 \mathrm{~mm}$ CL individual provides maximums of 15.18 and $12.28 \mathrm{~mm}$, respectively (Broadhurst et al., 2004).

For every deployment (4-8 per day), the $20 \mathrm{~mm}$ grid was randomly allocated to one of the paired trawls and secured within the aluminum frame (using cable ties). Either the 16 or $18 \mathrm{~mm}$ grids were then alternately secured to the remaining trawl. The two trawls were simultaneously deployed for standard commercial durations of $60 \mathrm{~min}$. The grids were then reordered as above for subsequent deployments. Over six days fishing, we completed 17 replicate paired deployments of both the 16 and $18 \mathrm{~mm}$ grids against the conventional $20 \mathrm{~mm}$ grid.

Catches were separated and the total weight of school prawns recorded. All bycatch species and approximately $500 \mathrm{~g}$ of school prawns were transferred to a laboratory. School prawns were counted, weighed, and a subsample ( $\mathrm{n}=$ approximately 100$)$ measured for CL (to the nearest $1 \mathrm{~mm}$ ) and used to calculate the total weight and mean CL per deployment. Fish were separated by species, counted, weighed, and measured (total length; TL to the nearest $0.5 \mathrm{~mm}$ ).

Data for the numbers and weights of catches were separately analyzed using linear mixed models (LMM's). Prior 
(a) Wt of school prawns

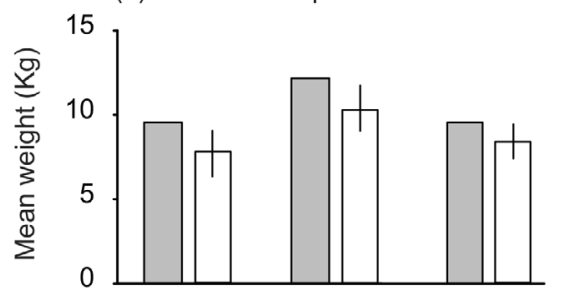

(c) No. of total fish

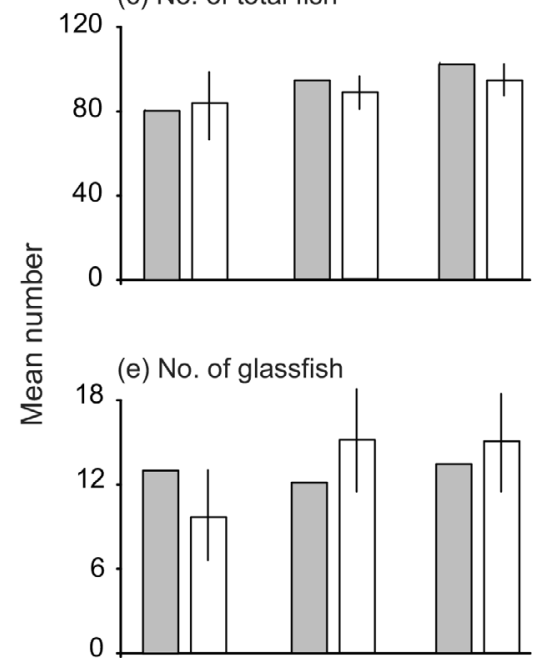

(g) No. of southern herring

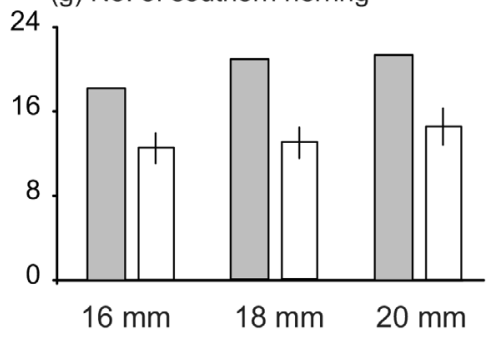

(b) Wt of total fish

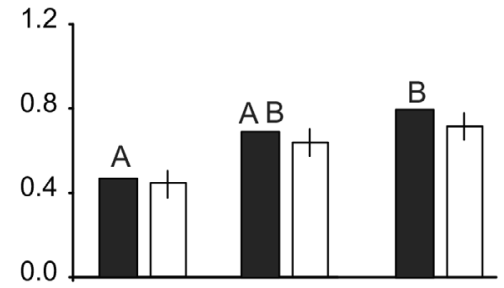

(d) No. of forktail catfish

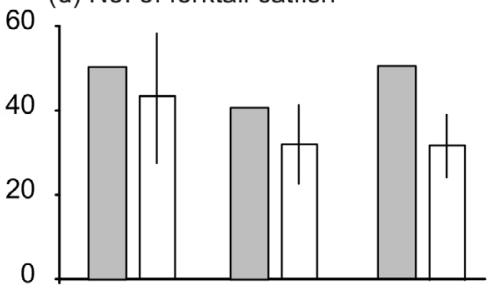

(f) No. of silver biddy

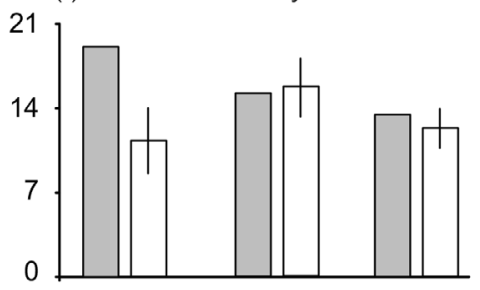

(h) No. of yellowfin bream

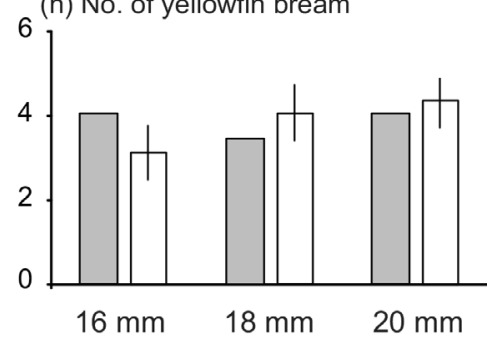

\section{Grids}

Figure 2.-Differences in predicted (shaded) and raw $( \pm \mathrm{SE}$, white) mean catches between grids for the (a) weight of school prawns, Metapenaeus macleayi, (b) weights and (c) numbers of total fish, and the numbers of (d) forktail catfish, Arius graeffei, (e) glassfish, Ambassis jacksoniensis and A. marianus, (f) silver biddy, Gerres subfaciatus, (g) southern herring, Herklotsichthys castelnaui, and (h) yellowfin bream, Acanthopagrus australis. Letters above the weight of total fish indicate the direction of differences detected in false-discovery-rate pairwise comparisons for the significant fixed effect of bar spaces in linear mixed models (black histograms; $p<0.05$ ).

to analyses, the numbers and weights of catches were log-transformed so that differences between bar spaces were modeled to act multiplicatively rather than additively. The mean individual mass and mean CL of school prawns per deployment were analyzed in their raw form. All models included "bar spaces" as fixed, while "trawls", "days", and the interaction between "deployments" and days were random. The significance of bar spaces was determined using a Wald $F$-test. Predicted mean numbers and weights were obtained by back-transforming log-predictions from the LMM's, and any significant differences were subsequently explored using the Benjamini-Hochberg-Yekutieli procedure to control the false discovery rate (FDR) (Benjamini and Yekutieli, 2001). Both the predicted and raw $( \pm \mathrm{SE})$ means of interest were graphed.

For individual species, the proportion of the total paired catch (for each length class) retained in the trawl with the $20 \mathrm{~mm}$ grid was calculated. A curve was fitted to these proportions under the assumption that the grids had logistic selection. Geometric similarity was assumed so the selection curves scaled proportional to the bar spacing. Curves were fitted using maximum likelihood, with over-dispersion correction to allow for between-haul variability (Millar et al., 2004).

\section{Results}

In total, during the 34 paired tows across six days, $496 \mathrm{~kg}$ of school prawns $(5-25 \mathrm{~mm} \mathrm{CL})$ and $44 \mathrm{~kg}$ of fish (or 4,447 individuals) were caught. The fish included more than 13 species, but only five species/groups were caught in sufficient quantities ( $>95 \%$ of the total) to permit analyses (Fig. 2).

There were no significant differences between the 16,18 , and $20 \mathrm{~mm}$ grids for the mean ( \pm SE) CL's $(14.35$ $\pm 0.30,14.40 \pm 0.30$, and $14.42 \pm 0.29$ $\mathrm{mm}$ CL) of school prawns or their individual mass per deployment (LMM, P $>0.05$, Table 1, Fig. 2a). Selection curves were attempted for school prawns; but the null hypothesis of no relationship between the proportion and the CL's of school prawns was accepted for bar spaces $(\mathrm{P}>0.1$, Fig. 3a).

Forktail catfish, Arius graeffei, was the dominant bycatch $(47 \%$ of the total and 5.0-10.0 cm TL), followed by glassfish, Ambassis jacksoniensis and $A$. marianus $(16 \% ; 4.5-10.0 \mathrm{~cm}$ TL), silver biddy, Gerres subfaciatus $(15 \% ; 3.5-15.5 \mathrm{~cm} \mathrm{TL})$, southern herring, Herklotsichthys castelnaui 
Table 1.-Summaries of Wald- $F$ statistics from linear mixed models assessing the importance of the fixed effect of Nordmøre grid "bar spaces" (conventional 20 vs 16 vs $18 \mathrm{~mm}$ grids) in explaining variability among catches. Excluding the mean carapace length (CL) and mass of school prawns, Metapenaeus macleayi, all other numbers and weights were log-transformed.

\begin{tabular}{lc}
\hline Item & Wald F \\
\hline Wt of school prawns & 2.37 \\
Mean CL of school prawns & 0.16 \\
Mean individual mass of school prawns & 0.68 \\
Wt of total fish & $3.44^{1}$ \\
No. of total fish & 1.80 \\
Wt of forktail catfish, Arius graeffei & 0.95 \\
No. of forktail catfish & 1.54 \\
Wt of glassfish, Ambassis jacksoniensis and A. marianus & 0.56 \\
No. of glassfish & 0.23 \\
Wt of southern herring, Herklotsichthys castelnaui & 1.21 \\
No. of southern herring & 0.38 \\
Wt of silver biddy, Gerres subfaciatus & 1.05 \\
No. of silver biddy & 2.14 \\
Wt of yellowfin bream, Acanthopagrus australis & 0.80 \\
No. of yellowfin bream & 0.63 \\
\hline
\end{tabular}

${ }^{1} \mathrm{P}<0.05$

(a) School prawns

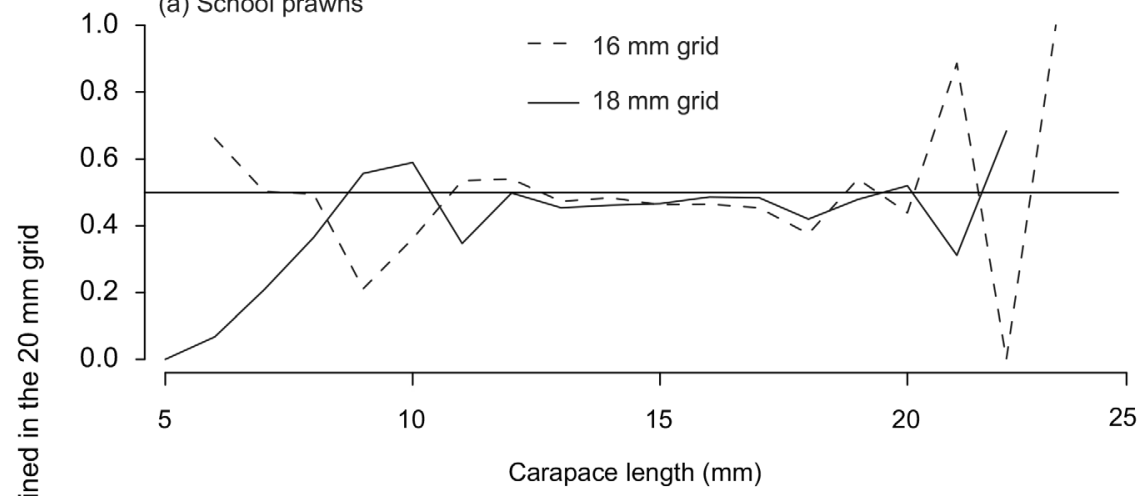

(b) Southern herring

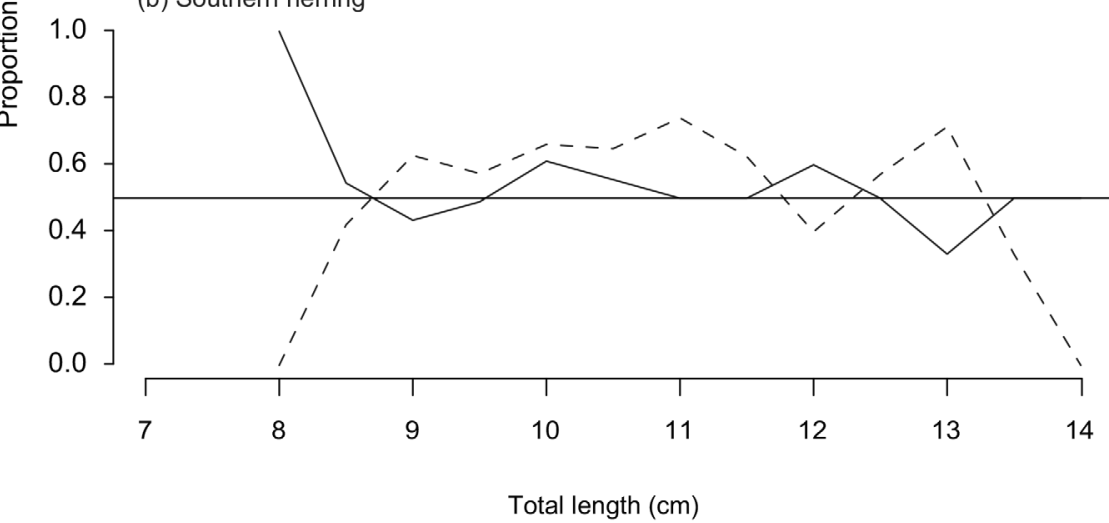

Figure 3.-Plots of the proportions of (a) school prawns, Metapenaeus macleayi and (b) southern herring, Herklotsichthys castelnaui at encountered sizes retained in the $20 \mathrm{~mm}$ grid during paired comparisons with the 16 and (dashed lines) 18 $\mathrm{mm}$ grids (solid lines).
$(12 \% ; 7.5-15.5 \mathrm{~cm} \mathrm{TL})$, and yellowfin bream, Acanthopagrus australis (5\%; 5.5-17.5 cm TL) (Table 1, Fig. 2d-h). The LMM's detected significant differences among grids for the weight of total fish (Table 1, P $<0.01$ ), with FDR's revealing that the $16 \mathrm{~mm}$ grid caught 26\% less than the $20 \mathrm{~mm}$ grid $(\mathrm{P}<0.05)$, but no differences between these grids and the $18 \mathrm{~mm}$ grid $(\mathrm{P}>$ 0.05 , Fig. 2b). The number of total fish followed a similar mean trend among grids with up to $20 \%$ fewer in the 16 than the $20 \mathrm{~mm}$ grid, but this was not significant (LMM, P > 0.05, Table 1, Fig. 2c). Similarly, there were no significant differences in the predicted mean weights or numbers of individual species (only numbers are plotted for brevity), but some were lower in the $16 \mathrm{~mm}$ grid (LMM, P > 0.05, Table 1, Fig. 2e, f). There were no differences in size selectivity among grids for any fish (southern herring graphed as an example, $\mathrm{P}>0.1$, Fig. 3b).

\section{Discussion}

The data presented here contribute toward the existing literature describing technical factors affecting Nordmøre grid performances in penaeid-trawl fisheries (Broadhurst and Kennelly, 1996; Brewer et al., 1998; Silva et al., 2012; Kennelly and Broadhurst, 2014). More specifically, it is clear that bar spaces can be reduced to a size close to the $\mathrm{CH}$ of the largest school prawns while still consistently maintaining target catches, but with some reduction in bycatch. These observations can be discussed in terms of the species caught and their morphology, possible behaviors, and orientations at the Nordmøre grid, and then used to propose other refinements.

The maintenance of school prawn catches and the lack of any relative differences in size selection as bar spaces decreased implies that irrespective of their initial contact, all individuals were quickly orientated parallel to the angled bars (to pass through) and conceivably for many, across their width because this is their narrowest dimension. A contributing factor may have been the guiding funnel, which 
directed the entire catch to the base of the grid and ensured maximum exposure to the surface. In some cases, the absence (or associated design issues) of such a guiding panel could be a contributing factor in the escape of penaeids from other grids with relatively much larger bar spaces (Broadhurst et al., 2002).

Fish also would have been similarly directed to the base of the grids, and so the significant reduction in the weight of bycatch but not numbers (although means were reduced) implies a few larger individuals passed through the escape exit of the $16 \mathrm{~mm}$ grid. However, although not significant, the abundant species that apparently contributed towards these reductions mostly comprised individuals with dimensions much smaller than the bar spaces. Specifically, all forktail catfish were very small $(5.0-10.0 \mathrm{~cm} \mathrm{TL})$, while both species comprising glassfish have maximum TL's of approximately 7 and $10 \mathrm{~cm}$, respectively and widths considerably less than $16 \mathrm{~mm}$. Similarly, even a $15.5 \mathrm{~cm}$ TL southern herring (maximum size observed here and typically present in the river) has a maximum width $<16 \mathrm{~mm}$ (Broadhurst et al., 2012).

Considering the above, and the lack of any evidence of size selection, it is possible that at least some small fish (across all sizes) were able to actively swim forward after detecting the narrower $16 \mathrm{~mm}$ bars in the grid and out of the exit-implying a behavioral response. A contributory influence may have been the proximity $(<1.2 \mathrm{~m})$ of the grid to the end of the codend (Broadhurst et al., 2002). Previous studies have shown that at this distance there is significant displacement of water forward that can assist small fish to maintain position (Broadhurst et al., 1999; 2002). Any such effects might have facilitated some small fish, including glassfish and southern herring, to escape via the grid opening, and might also contribute towards the consistent passage of all small fish through the anterior section of the square-mesh codend (Broadhurst et al., 2002).

The results from this study imply that as a starting point, the bar spaces in Nordmøre grids (and perhaps other similar separating grids, such as those used to reduce catches of sea turtles) can be reduced to a size approaching the maximum $\mathrm{CW}$ of the targeted penaeids. Doing so will not only maintain the escape of large animals (e.g., sea turtles and elasmobranchs), but might also facilitate some behavioral escape of teleosts similar in size to the penaeids and certainly mechanical separation among those individuals that are larger (often encountered at different areas and times; Broadhurst et al., 1996). The latter is an important consideration because ideally, wherever possible, a single BRD would fulfill species-selectivity requirements, and especially for small-scale fisheries with multi-trawl configurations that generally preclude incorporating complex BRD combinations. Such work warrants ongoing attention, because despite historical efforts, bycatch in many fisheries remains a global concern that still requires applied solutions (Hall and Mainprize, 2005).

\section{Acknowledgments}

This study was funded by the New South Wales (NSW) Department of Primary Industries. Thanks are extended to the (NSW) Professional Fishing Association, Don Johnson, and Craig Brand.

\section{Literature Cited}

Benjamini, Y., and D. Yekutieli. 2001. The control of the false discovery rate in multiple testing under dependency. Ann. Stat. 29:1165-1188.

Brewer, D., N. Rawlinson, S. Eayrs, and C. Burridge. 1998. An assessment of by- catch reduction devices in a tropical Australian prawn trawl fishery. Fish. Res. 36:195-215. (doi: https://doi.org/10.1016/ S0165-7836(98)00096-4)

Broadhurst, M. K. 2000. Modifications to reduce bycatch in prawn trawls: A review and framework for development. Rev. Fish Biol. Fish. 10:27-60.

S. J. Kennelly, and B. Isaksen. 1996. Assessments of modified codends that reduce the by-catch of fish in two estuarine prawn-trawl fisheries in New South Wales, Australia. Fish. Res. 27:89-111. (doi: https:// doi.org/10.1016/0165-7836(95)00457-2). and S. Eayrs. 1999

Flow-related effects in prawn-trawl codends: potential for increasing the escape of unwanted fish through square-mesh panels. Fish. Bull. 97:1-8.

M. I. Kangas, C. Damiano, S. A. Bickford, and S. J. Kennelly. 2002. Using composite square-mesh panels and the Nordmøre grid to reduce bycatch in the Shark Bay prawn-trawl fishery, Western Australia. Fish. Res. 58:349-365. (doi: https://doi. org/10.1016/S0165-7836(01)00390-3). R. B. Millar, D. J. Young, M. E L. Wooden, and S. Rowland. 2004. Atypical size selection of captive school prawns, Metapenaeus macleayi, by three recreational fishing gears in south-eastern Australia. New Zealand J. Mar. Freshw. Res. 38:755-766. (doi: https://doi.org/10.1080/00288330.2004. 9517275).

D. J. Sterling, and R. B. Millar. 2012. Short vs long penaeid trawls: Effects of side taper on engineering and catching performances. Fish Res 134:73-81. (doi: https://doi.org/10.1016/j.fishres.2012.08.009).

Hall, S. J., and B. M. Mainprize. 2005. Managing by-catch and discards: how much progress are we making and how can we do better? Fish Fish. 6:134-155. (doi: https://doi. org/10.1111/j.1467-2979.2005.00183.x).

Isaksen, B., J. W. Valdemarsen, R. B. Larsen, and L. Karlsen. 1992. Reduction of fish by-catch in shrimp trawl using a rigid separator grid in the aft belly. Fish. Res. 13:335-352.(doi:https://doi.org/10.1016/01657836(92)90086-9).

Kennelly, S. J., and M. K. Broadhurst. 2014 Mitigating the bycatch of giant cuttlefish $\mathrm{Se}$ pia apama and blue swimmer crabs Portunus armatus in an Australian penaeid-trawl fishery. End. Species Res.26: 161-166. (doi: https://doi.org/10.3354/esr00639).

Millar, R. B., M. K. Broadhurst, and W. G. MacBeth. 2004. Modelling between-haul variability in the size selectivity of trawls. Fish. Res. 67:171-181. (doi: https://doi.org/10.1016/j. fishres.2003.09.040j).

Silva, C. N. S., M. K. Broadhurst, J. H. Dias, A P. Cattani, and H. L. Spach. 2012. The effects of Nordmøre grid bar spacings on catches in a Brazilian artisanal shrimp fishery. Fish. Res. 127-128:188-193. (doi: https://doi.org/ 10.1016/j.fishres.2012.01.004). 